\title{
El Gas de Lutitas (Shale Gas) en México. Recursos, explotación, usos, impactos ${ }^{1}$ Shale Gas in Mexico. Resources, Exploitation, Uses and Impacts
}

\author{
Angel de la Vega Navarro* \\ Jaime Ramírez Villegas**
}

\begin{abstract}
* Profesor e investigador
del Posgrado de Economía y del Posgrado de Ingeniería,

Campo de Conocimiento:

Energía, UNAM. «adelaveg@unam.mx»

** Maestro en Economía por la UNAM.
\end{abstract}

Journal of Economic Literature (JEL): L71, L95, Q42

Palabras clave:

Minería

Producción y suministro de gas

Energías alternativas

$$
\begin{gathered}
\text { Keywords: } \\
\text { Mining }
\end{gathered}
$$

Gas Utilities

Alternative Energy Sources

\section{Resumen}

Los hechos y procesos energéticos se han acelerado, resultado en buena parte de innovaciones y avances tecnológicos, tal como ha sucedido en el campo del gas natural no convencional en Estados Unidos, creando expectativas sobre la posibilidad de replicar sus logros en otras latitudes. Precisamente, información proveniente del exterior ha colocado a México en un lugar importante en cuanto a la existencia en su territorio de importantes recursos prospectivos del gas de lutitas o shale gas. Con base en ello se ha dicho que esos recursos pueden contribuir a un mejor suministro energético e impactar favorablemente el desarrollo nacional y local.

Reconociendo la importancia de los logros y realizaciones de Estados Unidos, analizados en el trabajo, no es posible sostener que se puede replicar la "revolución del shale gas", producto de condiciones y factores técnicos, económicos, institucionales y organizativos específicos de ese país. Una estrategia para detonar la eventual explotación de esa fuente de energía exige un conocimiento profundo de la situación estructural de la industria del gas natural. También es necesario entender aspectos técnicos referentes a sus procesos de producción, ya que son indispensables para elaborar planteamientos económicos, organizativos y regulatorios.

Es en un marco integral de políticas energéticas, ambientales y tecnológicas en donde debe analizarse y discutirse la posible explotación del shale gas por entidades públicas o privadas. De confirmarse la existencia de recursos técnica y económicamente recuperables y una vez estudiados exhaustivamente los

${ }^{1}$ Una primera versión de este trabajo se presentó en la Mesa de Discusión "La Revolución del Shale Gas" organizada por el Embajador Jorge Eduardo Navarrete en el Centro de Investigaciones Interdisciplinarias en Ciencias y Humanidades, CIICH-UNAM, el 25 de abril 2013. En aquella versión participaron Rosalba M. Ortiz, doctorante del Posgrado de Economía de la UnAm y Cuauhtémoc Solórzano Santana, egresado de la Maestría en Ingeniería de esta misma universidad.Al agradecer aportaciones, comentarios y sugerencias los autores asumen la entera responsabilidad de este trabajo. 
impactos e implicaciones ambientales, es necesario además construir un marco regulatorio específico y las instituciones correspondientes que aseguren un adecuado desarrollo.

\section{Abstract}

Energy facts and processes have accelerated, mainly as a result of innovations and technological advances. A good example is what has recently taken place in the United States in the field of unconventional natural gas, producing expectations about the possibility of replicating the shale revolution in other countries. Precisely, information coming from the Energy Information Agency recently positioned Mexico at the top world places concerning shale gas resources in its territory. Based on this information official statements have been made about the possibility of these resources to contribute to a better energy supply and to impact economic development both at national and local levels.

Recognizing the importance of the US successes and performances, a product of specific combination of conditions and factors analyzed in the article, it is not possible to sustain that they could be replicated in Mexico. A strategy to detonate the eventual exploitation of that energy source demands a deep knowledge of the structural situation of the natural gas industry. It is also necessary to understand technical aspects concerning unconventional gas production processes, to be able to understand the way economic, organizational and regulatory issues are structured.

It is within an integral framework of energy, environmental and technological policies that the possible exploitation of shale gas by public and private actors should be analyzed and discussed. Once the existence of resources technically and econonomically recooverable is fully confirmed and the environmental impacts of their exploitation fully assessed, it is also necessary to build or reinforce a specific institutional and regulatory framework in order to guarantee an adequate development of this sector.

\section{Introducción}

os hechos y procesos energéticos se han acelerado, en buena parte como resultado de innovaciones y avances tecnológicos. Un ejemplo es lo que ha sucedido en el campo del gas natural en el presente siglo. De una situación calificada de déficit estructural en América del Norte se ha pasado a una autosuficiencia probable en un futuro cercano e, incluso, a posibles exportaciones netas de Estados Unidos cuando para este país se preveía hace pocos años una creciente dependencia del gas canadiense y, posteriormente, la importación de fuertes cantidades de gas natural licuado (GNL).

El rápido desarrollo del gas no convencional ha venido a cambiar radicalmente esas previsiones con consecuenciaspara otras regiones. Es posible que la producciónse desarrolle también en otros países, aunque no es seguro que lo haga 
con la misma extensión y a la misma velocidad. Además de efectos en el ámbito propiamente energético, el auge del gas de lutitas o shale gas ${ }^{2}$ en Estados Unidosha impactado el costo de la materia prima utilizada en la petroquímica y la competitividad de esta industria. Se vislumbra, además, una utilización importante en el transporte.En el plano internacional se ha presentado ya una reorientación de los flujos del comercio energético mundial, lo cual tendrá diversas implicaciones económicas y geopolíticas.

Información proveniente del exterior, que examinaremos más adelante, coloca a México en un lugar importante en cuanto a la existencia en su territorio de importantes recursos prospectivos de gas natural no convencional, en particular shale gas. Con base en esa información y trabajos de Pemex, desde el sexenio pasado se han hecho planteamientos acerca de las posibilidades de esos recursos para contribuir a un mejor abastecimiento energético y producir variados impactos sobre el desarrollo en el plano nacional y en ámbitos locales. Es importante que desde diferentes perspectivas se profundicela información y las propuestas y, sobre todo, que se contribuya a un debate ilustrado. Esto es lo que nos proponemos en este trabajo, examinando sucesivamente los siguientes puntos:

\section{El gas de lutitas. Aspectos técnicose impacto ambiental \\ 2. La revolución del shale gas en Estados Unidos \\ 3. El potencial de shale gas y su significado económico para México \\ 4. Posibilidades y retos para su desarrollo}

El análisis de aspectos políticos, técnicos y de aquellos referentes al proceso de producción de gas natural no convencional es indispensable para entender planteamientos económicos, organizativos y regulatorios. Serán a éstos, sin embargo, a los que se les dará una mayor atención en este trabajo. En este sentido, el planteamiento básicoconsiste en afirmar que el diseño de una estrategia para detonar la producción de gas de lutitas en México exige el conocimiento estructural de la industria del gas natural. Con base en ese conocimiento será posible diseñar políticas que permitan su impulso y desarrollo. No será posiblereplicar, como en ámbitos oficiales se ha pretendido, la "revolución del shale gas" que se ha dado en Estados Unidos, resultado de condiciones técnicas, económicas, institucionales y organizativasespecíficas a ese país.

Con las reformas que han culminado en la primera quincena del mes de agosto de 2014 , ha cambiado radicalmente el marco en el cual se desarrollarán las actividades de las industrias energéticas al quedar abiertas en su totalidad a la entrada de nuevos actores. Los que ya se encuentran en ellas, como Petroleos Mexicanos (Pemex) y Comisión Federal de Electricidad (CFE), deberán adaptarse a un entorno competitivo y a las nuevas reglas que se derivan de los cambios constitucionales realizados en diciembre 2013 y de las leyes secundarias que enmarcarán en adelante la actividad de los actores energéticos. Los resultados no se verán de manera inmediata: la implementación de las reformas será un proceso

2 En el trabajo se utilizarán esas dos expresiones de manera indistinta. 
largo con incertidumbre y numerosos riesgos. En este trabajo se tomará en cuenta el nuevo marco y sus implicaciones, a sabiendas de que sobre todo ello se abre también un proceso largo de estudio, de investigación y de aprendizaje.

\section{El gas de lutitas. Aspectos técnicos e impacto ambiental}

\subsection{Su ubicación en el campo de los hidrocarburos}

El gas natural es una mezcla de hidrocarburos simples que se encuentra en estado gaseoso, en condiciones ambientales normales de presión y temperatura. Se compone principalmente de gas metano en $95 \%$, con cantidades variables de etano, propano, butano y otros gases. Es ampliamente utilizado a nivel mundial en los sectores eléctrico, petrolero, industrial, residencial, servicios y transporte.

La producción y exploración de gas se clasifica en yacimientos convencionales y no convencionales. Considerando las características geológicas, en los yacimientos convencionales el gas se encuentra atrapado en una estructura de roca porosa limitada por una capa de roca impermeable que evita que el gas escape a la superficie. Los yacimientos no convencionales son más extendidos y consisten en una acumulación de capas sedimentarias de baja permeabilidadque atrapan el gas entre ellas. Las características geológicas de los yacimientos no convencionales hacen difícil la extracción, por lo que su producción no es económicamente rentable a menos que se utilicen tratamientos de estimulación y tecnologías especiales para su recuperación.

Gráfica 1

Formas de Extracción del Gas Natural

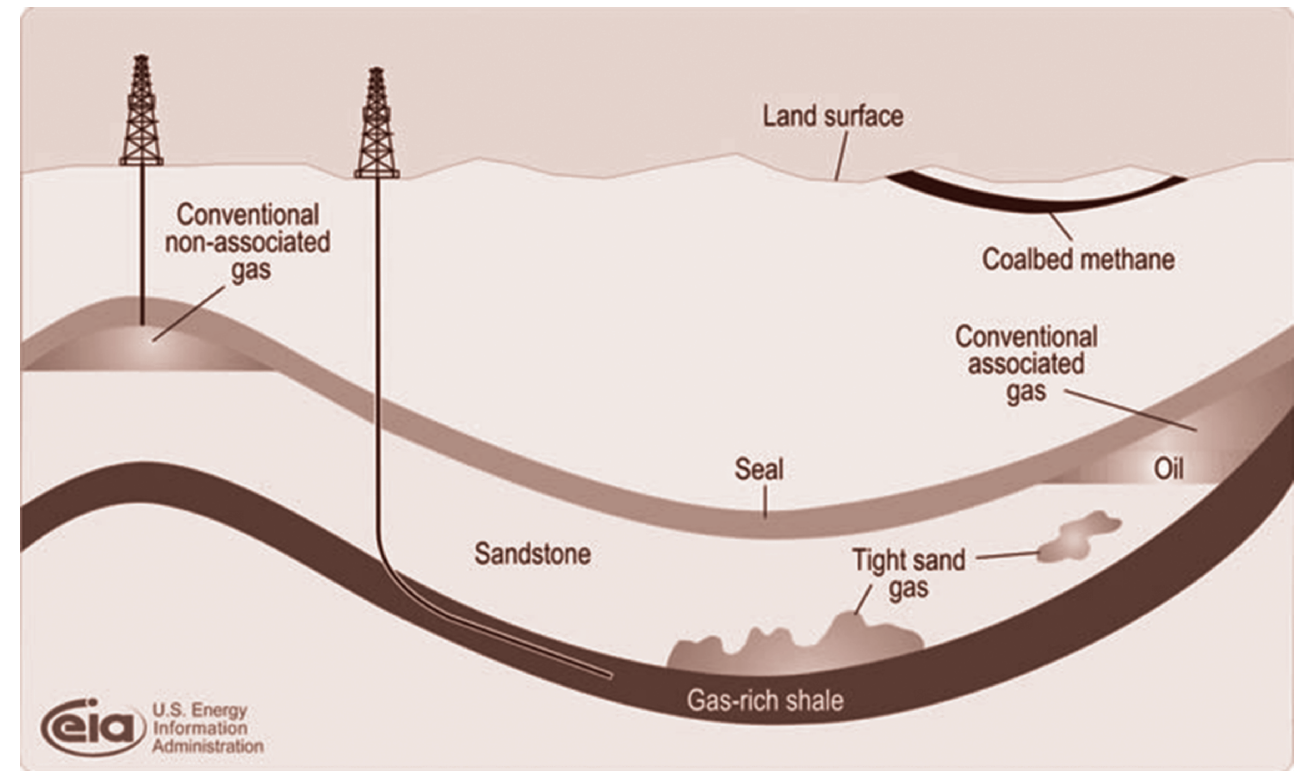

Fuente: International Energy Agency.

El shale gas se encuentra en yacimientos compuestos predominantemente por esquistos o pizarras, que son rocas de baja permeabilidad, por lo que su producción en cantidades comerciales demanda técnicas de fracturación para 
aumentar su permeabilidad y poder llegar a los poros que almacena el gas. Por todo ello, el shale gas se clasifican entre los recursos no convencionales. ${ }^{3}$

La gráfica 1 muestra los tipos de yacimientos de gas natural, que son clasificados en convencionales y no convencionales.

\subsection{Proceso de producción de shale gas}

La tecnología y el proceso de producción de shale gas son singulares y complejos cuando se les compara con los yacimientos convencionales. En términos generales el proceso puede describirse de la siguiente manera.

Para extraer shale gas, el primer paso es la evaluación de los recursos o exploración; inicia recopilando datos geológicos, geoquímicos y sísmicos existentes para analizarlos. De ser necesario se analizan investigaciones sísmicas complementarias para afinar las conclusiones, decidiendo la perforación de sondeo o el abandono de la zona sino se considera apropiada. La perforación de investigación es el único medio fiable para poder determinar la presencia de hidrocarburos y la viabilidad de su extracción.

El segundo paso es la perforación, misma que se hace verticalmente hasta alcanzar la capa de gas. Dependiendo del espesor de ésta, se decide la conveniencia de perforar más pozos verticales o de hacerlo horizontalmente (en trayectorias que superan los 1000 metros en línea horizontal) a fin de aumentar el contacto con la capa de gas. Para minimizar el riesgo de contaminación seintroduce en el pozo una tubería de acero desde la superficie hasta el final del pozo y posteriormente se inyecta cemento entre el espacio que queda entre la tubería y las paredes del pozo, de tal suerte que el pozo queda aislado de todas las rocas y acuíferos que haya atravesado. Cabe mencionar que los acuíferos se encuentran en promedio a 500 metros de profundidad, mientras que los pozos de shale gas están a 1500 y 2000 metros.

Asegurado el aislamiento del pozo, el tercer paso consiste en elproceso de estimulación mediante la fracturación hidráulica (fracking). Este procedimiento consiste en que una vez que la perforación ha alcanzado la capa de gas, se inyecta una mezcla de grandes cantidades de agua, arena y químicos a alta presión ( $98 \%$ de agua y arena y $2 \%$ de aditivos, en promedio) conocida como fluido de fracturación. Esta acción provoca pequeñas fracturas en las lutitas y libera el gas atrapado en la roca.

Finalmente el cuarto paso consiste en la extracción. Una vez que la presión del agua inyectada se reduce, el agua residual contiene fragmentos de metales pesados y radioactivos que se mezclan con los reflujos de la roca, llevándolos a la superficie con el gas extraído. La mayor parte del reflujo de la fracturación, se transporta desde las plataformas de perforación hacia los puntos de tratamiento y eliminación. En la actualidad está presente el reto por desarrollar nuevas y más

3 Una exposición amplia de hidrocarburos en yacimientos no convencionales puede ser consultada en Javier Estrada Estrada [2013]. 
eficientes técnicas para procesar el fluido in situ a fin de reducir los costos y los impactos ambientales.

La perforación horizontal y la fracturación hidráulica han ampliado significativamente la capacidad de recuperación de plays de baja permeabilidad. Sin embargo, en estos yacimientos el factor de recuperación se sitúa entre 4 y $10 \%$, que contrasta con 70 u $80 \%$ que alcanzan los yacimientos convencionales (Sandrea Rafael, 2012). En este mismo sentido, los yacimientos de shale gas presentan tasas anuales de declinación altas, del orden de 29 y $52 \%$ anual ya que con el tiempo el gas tiende a quedarse atrapado nuevamente y exige seguir repitiendo el proceso de manera regular a fin de evitar la caída acelerada de la producción (RodgersDeborah, 2013). El proceso de extracción demanda entonces inversiones cada vez mayores para extraer cada vez menos producción.

\subsection{Impactos ambientales}

El proceso de extracción descrito, entraña una serie de problemas en cuanto al impacto sobre el medio ambiente. Las nuevas técnicas de perforación y la fractura hidráulica han cambiado la escena energética en Estados Unidos, pero estudios científicos han puesto en evidencia la contaminación del agua en suelo y subsuelo y en general efectos sobre la calidad del agua relacionada con la explotación del shale gas. ${ }^{4}$

\subsubsection{El problema del agua y la contaminación}

Uno de los principales problemas que genera la producción del gas de lutitas es la gran cantidad de agua que demanda, en detrimento de usos alternativos que se le puede dar a la misma, como el consumo humano o la actividad agrícola. En términos generales, mientras la perforación convencional demanda agua para enfriar y lubricar el cabezal de perforación así como eliminar el lodo resultante,la fracturación hidráulica demanda alrededor de diez veces más. El cuadro siguiente muestra las demanda de agua por pozo en distintos plays de lutitas en Estados Unidos; en ellos la casi la totalidad del agua demandada es para la fracturación de la roca. El mayor consumo es al inicio de la producción y luego se intenta reducir la cantidad de agua requerida en la fracturación.

\begin{tabular}{|l|c|c|c|}
\hline Cuadro 1 Uso de agua por pozo para perforación y fracturación (en millones de litros) \\
\hline Play de gas de lutitas & $\begin{array}{c}\text { Perforación: Volumen } \\
\text { de agua por pozo }\end{array}$ & $\begin{array}{c}\text { Fracturación: Volumen } \\
\text { de agua por pozo }\end{array}$ & $\begin{array}{c}\text { Total: Volumen de agua } \\
\text { por pozo }\end{array}$ \\
\hline Barrett & 1.5 & 8.7 & 10.2 \\
\hline Fayetteville & 0.2 & 11.0 & 11.2 \\
\hline Haynesville & 3.8 & 10.2 & 14.0 \\
\hline Marcellus & 0.3 & 14.4 & 14.7 \\
\hline
\end{tabular}

Fuente: Taha Murtuza Husain et. al.(2011).

4 Cf. Avner Vengosh et al. (2013). 
Un estudio realizado en Estados Unidos (Freyman Monika, 2014) sobre 39294 pozos de petróleo y gas de lutitas, fracturados entre febrero de 2011 y mayo de 2013, pone en evidencia hechos alarmantes. Alrededor de la mitad de esos pozos se encuentran en regiones con una "alta o extremadamente alta" tensión por el agua $^{5}$ y más de $55 \%$ en regiones que experimentan sequía. En algunos estados como Colorado o California, la proporción de pozos en zonas con extremadamente alta tensión por el agua llegó a 97\% de los pozos. En Texas, el estado con la más elevada concentración de la actividad del fracking, 52\% de los pozos se encontraban en ese tipo de regiones. A lo anterior se agrega que el desarrollo del shale gas depende en gran parte de agua subterránea, generalmente menos regulada que la de la superficie: $36 \%$ de los pozos fracturados, según el mencionado estudio, se sitúan en regiones que experimentan ya agotamiento de agua subterránea.

El agua residual que entraña el proceso de extracción debe ser desechada y reciclada. Existen preocupaciones por los derrames del agua contaminada en la superficie terrestre: está latente la posibilidad de que estos derrames se filtren y afecten los mantos acuíferos que se ubiquen a poca profundidad. También se presenta conectividad entre las formaciones profundas de shale gas y los acuíferos de agua potable cercanos a la superficie. En cuanto a los químicos que son inyectados a los yacimientos, se emplean más de 2500 productos que contienen más de 750 tipos de químicos. Muchos de ellos son desconocidos ya que están protegidos por las leyes de propiedad intelectual y no es posible determinar sus posibles impactos al medio ambiente. A este respecto, es indispensable avanzar en una mejor información y mayor transparencia, en particular para que las empresas dedicadas a la explotación de shale gasinformen al público sobre las sustancias químicas tóxicas usadas en sus procesos.

\subsubsection{El shale gas y las emisiones de GEI}

Un estudio realizado en la Universidad de Cornell (Howarth R. W., Santoro R., 2011) concluyó que en un horizonte de 20 años, el impacto de gases de efecto invernadero (GEI) por el shale gas podría ser por lo menos $20 \%$ mayor que el del carbón. Inclusive se ha estimado que cuando se considera en conjunto la extracción, procesamiento y transporte de gas natural, y se compara con otros combustibles en términos de emisiones totales de GEl, el impacto de shale gas es mayor que el del gas convencional, el carbón y el petróleo

Existen estudios que sostienen que la producción de shale gas no tiene grandes impactos al medio ambiente, al menos no mayores a los que entraña alguna otra actividad ya probada en la producción de hidrocarburos. Por ejemplo, Jenner y Lamadrid (2012) opinan que en el caso de la sustitución del shale gas por el carbón, el primero genera mayores beneficios en la salud pública, la seguridad de los trabajadores, la protección ambiental, en el consumo del agua y la cantidad

\footnotetext{
5 Según la definición del World Resources Institute, Extremely high water stress significa que más de $80 \%$ del agua subterránea y de la superficie está ya asignada a usos industriales, agrícolas o municipales.
} 
de tierras. Esos autores sostienen, además que la tecnología será capaz de minimizar cada vez más los impactos de la producción del shale gas. Asimismo, productores de shale gas sostienen que el fracking disminuye la necesidad de tener grandes áreas destinadas a la extracción de gas natural. Afirman que los químicos utilizados en el proceso son benignos, las tuberías anticorrosivas y que el agua empleada se puede verter sin problemas al medio ambiente.

Los países que disponen de recursos, han tomado diferentes posturas.Algunos, como Estados Unidos, consideran que los impactos ambientales del shale gas pueden ser minimizados con una adecuada regulación de los procesos involucrados.Otros, como Francia, ${ }^{6}$ han frenado la exploración y producción de shale gas, aunque en este caso y en otros que se orientan en el mismo sentido continúa el debate debido a un motivo esencial: la seguridad energética.

El debate sobre las implicaciones medio ambientales del shale gas está presente, ya sea en Estados Unidos, donde el desarrollo de la industria ha crecido fuertemente los últimos años, o en países donde se puede producir shale gas pero deben enfrentar retos medioambientales y la oposición de buena parte de la sociedad. En aquellos donde la balanza se ha inclinado a favor de la producción de shale gas, han iniciado procedimientos regulatorios en materia de medio ambiente, mientras que otros han optado por no desarrollar este tipo de recursos.

En Europa, entre Polonia, que ha hecho del shale gas una prioridad nacional, y Francia, que prohibió la fracturación hidráulica, las controversias no han terminado. ' En el año 2000 fueron otorgados los primeros permisos de exploración y desde entonces ha habido progresos en Polonia, Reino Unido y Dinamarca. A partir de ellos, algunos se interrogan acerca del posible surgimiento de un modelo europeo para la explotación de shale gas, una de cuyas condiciones sería lograr la aceptación de la sociedad (Cornot-Gandolphe Sylvie,2013).

En las circunstancias señaladas y diversidad de situaciones, los estudios legales y regulatorios tienen una gran importancia para prevenir y mitigar los riesgos para el ambiente. Marcos regulatorios dinámicos, flexibles e innovadores son los que más posibilidades tendrán para la gestión de los riesgos vinculados a la explotación de shale gas (Olmstead Sh., Richardson N., 2014). A una regulación con esas características se agregan responsabilidades legales para obligar a las empresas a que reduzcan los riesgos que entraña su actividad. Según esos autores, en Estados Unidos muchas de las actividades relacionadas con la perforación no están reguladas o sólo lo están ligeramente; pero las empresas siempre tienen presente la amenaza de una demanda, en caso de que su actividad se traduzca en daños a personas o al medio ambiente. Regulación y responsabilidad legal no son excluyentes: pueden trabajar juntas para dar forma a patrones de comportamiento e incidir en la reducción de riesgos.

6 El Consejo Constitucional de este país validó el pasado 11 de octubre 2013 la ley del 13 de julio 2011 que prohíbe la fracturación hidráulica, considerada la única técnica disponible para extraer shale gas.

7 La Comisión Europea no se opone a la explotación del shale gas, pero ha recomendado principios mínimos para su explotación. El 22 de enero de 2014, por ejemplo, adoptó una recomendación para que se establezcan salvaguardias ambientales adecuadas en el caso del fracking. 


\section{La revolución del shale gas en Estados Unidos}

\subsection{Factores que permitieron su aparición}

En años recientes se ha hablado de un "boom" del shale gas impulsado por avances tecnológicos como el fracking; sin embargo, las técnicas de fractura para estimular la producción de gas y petróleo comenzaron desde el siglo 19 y se difundieron en los años 50 del siglo pasado. Con todo, fue hasta los años 90 y la primera década de este siglo cuando se lograron producciones en gran escala.

Antecedentes cercanos de éste método de extracción se remontan a la década de los 80 del siglo pasado, cuando un productor independiente estadounidense llamado George Mitchell, en un esfuerzo por reducir la caída en el suministro de gas que sufría su empresa, apostó por experimentar en una formación llamada Barnett Shale. Lo hizo a partir de un informe geológico, en el cual se mencionaba la existencia de gas atrapado en rocas. A finales de los años 90 se encontró una forma económica de aumentar las fracturas en esas rocas y liberar el gas atrapado.

Posteriormente la empresa de Mitchell se unió con Devon Energy, la cual tenía experiencia en la perforación horizontal. Esta tecnología permite perforar a cierta profundidad y continuar en otro ángulo que puede llegar a ser totalmente horizontal. A la fecha, el Instituto Americano del Petróleo (API) fija en Estados Unidos los estándares para el diseño de los tubos con los que se hacen las perforaciones, tales como las dimensiones y las tensiones máximas que deben resistir.

Los resultados ${ }^{8}$ de la explotacióna gran escala de shale gas en Estados Unidos, son producto de la combinación de factores que tuvieron lugar en un contexto específico. Las restricciones técnicas así como la abundancia de fuentes convencionales habían desalentado la exploración y producción de shale gas; fue a partir de los shocks petroleros de los setenta cuando se buscaron alternativas ante la demanda de energía empleando tecnologías que pudieran ser comerciales. Un conjunto de factores concurrió para llegar a esto: de carácter técnico, económico e institucional.

\section{Factores técnicos}

Los yacimientos de gas de lutitas necesitan de características específicas de carbón orgánico, madurez térmica, espesor de la roca, porosidad, profundidad y presión. En Estados Unidos se reúnen características geológicas favorables que no necesariamente se observan en otros países.

\footnotetext{
8 Además de los propiamente energéticos, los resultados son también de orden económico. Un in forme reciente (us Council of Economic Advisers, 2014) se afirma: "sólo los aumentos de la producción de petróleo y gas natural contribuyeron en más de $0.2 \%$ al crecimiento real del PIB en 2012 y 2013 ; el empleo en esos sectores creció en 133000 entre 2010 y 2013". Por otra parte, un estudio reciente (Arora V., Lieskovsky J., 2014) muestra que lo sucedido con el shale gas ha cambiado la relación entre la oferta de gas natural y la actividad económica en Estados Unidos: la respuesta de la producción industrial a un incremento del mismo tamaño en la oferta de gas natural es superior después de 2008 que antes de ese año.
} 
Se dispone en ese país, además, de estudios que muestran la ubicación de los recursos, identificando los que pueden ser realmente productivos, lo cual da más certidumbre a la industria y permite a los productores optimizar sus proyectos. Los estudios que periódicamente abordan y actualizan la tecnología empleada y la productividad de los pozos en operación son también de gran importancia.

Otros hechos a considerar son, por un lado, la existencia de una adecuada infraestructura de transporte asociada a la explotación del gas de lutitas, desde las áreas productoras hasta los centros de consumo. Por otro lado está la existencia de un fuerte sector de servicios, de tecnologías y equipos industriales relacionado con el sector petrolero. Todo eso ha apoyado los requerimientos de la exploración y producción de shale gas, la cual demanda múltiples perforaciones, fracturas, una intensa movilización de personal, plataformas, equipos de presión, tuberías de perforación, equipos de transporte de agua y fluidos, tanques de almacenamiento. Al mismo tiempo esos sectores y actividades se han visto impulsados por la producción de shale gas contribuyendo al empleo y al producto industrial de la economía de Estados Unidos.

Un factor más a considerar: la disponibilidad de agua es de gran importancia, ya que es esencial para mantener abierta la fractura y que el gas fluya de la roca. En este aspecto, Estados Unidos se encuentra mejor dotado que otros países, sin olvidar lo asentado más arriba.

\section{Factores económicos}

La industria del gas en Estados Unidos se desarrolla en entornos competitivos. Regulaciones sencillas han configurado una industria flexible, compuesta predominantemente por numerosas pequeñas y medianas empresas independientes. El papel que desempeñaron estas empresas, fue fundamental para impulsar el shale gas a una escala comercial superior. Esas pequeñas empresas fueron pioneras: pulieron la tecnología, establecieron nuevas prácticas, soportaron los riesgos del mercado y realizaron intensas perforaciones a través de grandes áreas con diferentes características geológicas. Fue hasta que la producción creció que empresas más grandes comenzaron ser atraídas al negocio, a pesar de que en un inicio mostraban poco interés.

La competitividad de la industria del gas natural se refleja también en sus precios, los cuales están desregulados y permiten reflejar las condiciones del mercado. No es de extrañar que el periodo 2000-2010 cuando los precios de gas natural oscilaban entre los 4.3 y 8.9 uSD/MMBTU, la producción de shale gas fuera en ascenso y que posteriormente contribuyera a mantener precios por debajo de 4 USD/MMBTU.

\section{Factores institucionales}

La producción de shale gas en Estados Unidos se ha incrementado de manera significativa en los últimos años. Entre los factores que se encuentran en la base de ese incremento se encuentran los avances tecnológicos apoyados por programas gubernamentales de impulso directo a la investigación y comercialización, 
la distribución de costos y riesgos en asociaciones público-privadas, así como la desregulación del mercado. Todo ello incentivó a compañías del ramo para apostar por tecnologías que permitiesen extraer gas, lo que no podía hacerse con la perforación convencional. El apoyo gubernamental se dio para la explotación tanto de arenas compactas y gas de lutitas, como de mantos carboníferos y fue el catalizador del avance hacia la tecnología actual.

Es fundamental tener presente que la estructura de los derechos de propiedad sobre los minerales en Estados Unidos, permite con relativa facilidad la explotación del recurso. En muchos países productores de petróleo y gas alrededor del mundo, los derechos de los minerales que están debajo de la superficie son generalmente propiedad de los Estados, haciendo que los procesos para obtener los derechos sean un desafío para los exploradores y desarrolladores. En buena parte de Estados Unidos, al ser los propietarios los dueños de los minerales alojados en su propiedad, las compañías productoras pueden directamente negociar con el propietario, reduciendo significativamente las barreras y el tiempo para obtener acceso a los derechos de los minerales.

En síntesis, un conjunto único de factores ha incidido en Estados Unidos para crear un ambiente de inversión favorable y lograr una producción masiva de gas no convencional. Entre ellos destacan: el apoyo gubernamental a actividades de investigación y desarrollo, las políticas para desregular los precios a boca de pozo, incentivar la inversión en recursos no convencionales, una geología favorable, un sector de servicios establecido, derechos de propiedad favorables, distribución de costos y riesgos en asociaciones público-privadas.

\subsection{Impactos e implicaciones del shale gas en Estados Unidos}

El "boom" de shale gas en Estados Unidos provocó una reconfiguración de la industria del gas en dicho país, dando un giro radical a los problemas de abasto que según sus previsiones enfrentarían en el corto y largo plazo.

Antes del auge del shale gas, los números en materia de gas natural en ese país no eran nada alentadores; baste mencionar que en el periodo 1990-2000 su producción únicamente crecía en $0.7 \%$ cada año, mientras que el consumo lo hacía en $2 \%$, lo cual se reflejó en un incremento de las importaciones de $9.4 \%$ anualmente. Ya con el auge del shale gas, ésta situación se ha revertido significativamente: en el periodo 2001 a 2012 la producción creció $2 \%$, el consumo 1.3\% y las importaciones cayeron en $2 \%$ anualmente (EIA, 2012).

En línea con lo anterior se estima que en el largo plazo la producción de gas continuará creciendo, impulsada fundamentalmente por el gas de lutitas, en una mayor proporción de lo que lo hará la demanda, logrando así una disminución de las importaciones. La gráfica 2 ilustra cómo, según la Energy Information Administration (EIA, 2012), la brecha entre demanda y producción se reducirá en los próximos años, de tal suerte que para el año 2022 Estados Unidos dejará de ser importador de gas, para convertirse en un exportador neto de dicho hidrocarburo, un fenómeno alentado principalmente por el shale gas. 


\section{Gráfica 2}

Producción y demanda de gas en Estados

Unidos (MMMpcd)

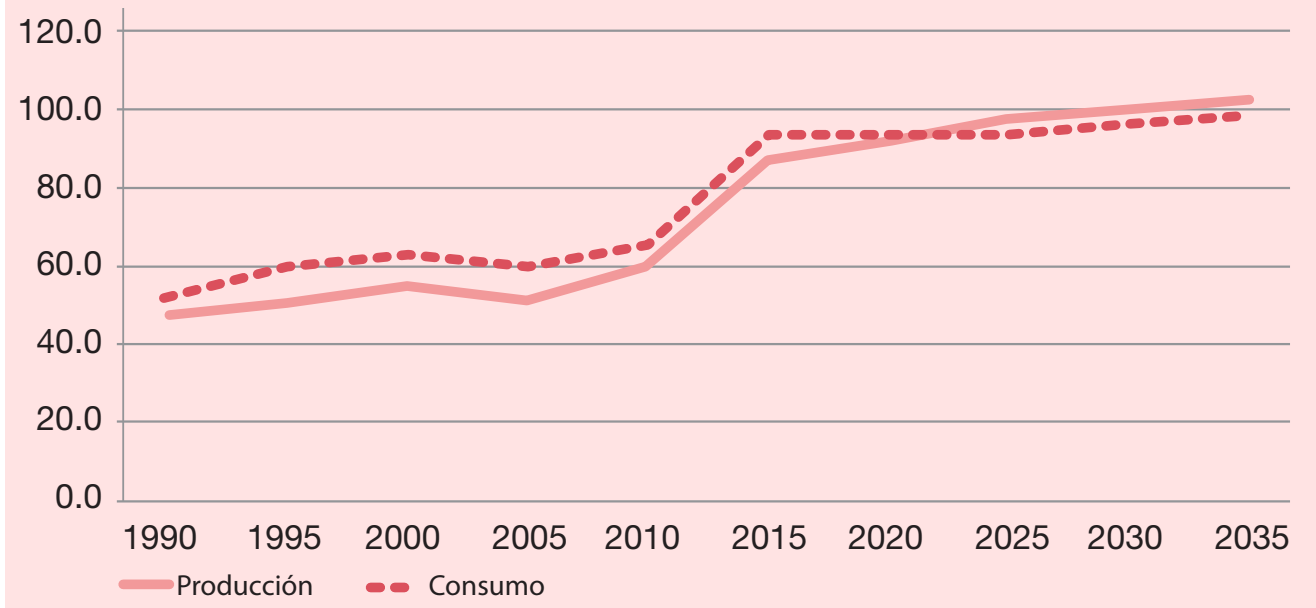

Fuente: elaboración propia con base en datos de la Annual Energy Outlook 2012, with Projections to 2035.

El hecho de que Estados Unidos deje de ser un importador de gas (sus importaciones provienen en $92 \%$ de Canadá a través de gasoductos) y se vuelva exportador neto, entrañará implicaciones en la configuración del comercio de gas en América de Norte. Es importante tener presente que de la producción de gas de Estados Unidos en 2013 (70.2 мmmpcd), 6.7\% se destinó a exportaciones fundamentalmente por gasoductos, con destino básicamente a Canadá y México (60 y $38 \%$ respectivamente de las exportaciones totales).

En este sentido, cobra especial relevancia el hecho de que productores estadounidenses tendrán mayores incentivos (considerando los precios bajos en América del Norte), para colocar sus excedentes de producción en mercados distantes bajo la forma de gas natural licuado (GNL). Al respecto en Estados Unidos hay indicios de cambios en la infraestructuracon miras a exportar gas en el corto plazo. Muestra de ello es que mientras en 2008 se tenía considerada la construcción de 42 terminales de regasificación, estimando que la producción se mantendría a la baja y la demanda crecería, pronto, con la incorporación del shale gas, dichos proyectos dieron marcha atrás. En la actualidad únicamente existen 12 terminales de regasificación y alrededor de 11 plantas de licuefacción están en etapa de evaluación para exportar gas. La gráfica 3 ilustra esto último: mientras las importaciones de GNL van a la baja, la capacidad de regasificación en los últimos años se ha mantenido constante. 
Gráfica 3

Importaciones de

GNL y Capacidad de regasificación en

Estados Unidos. mmmpcd

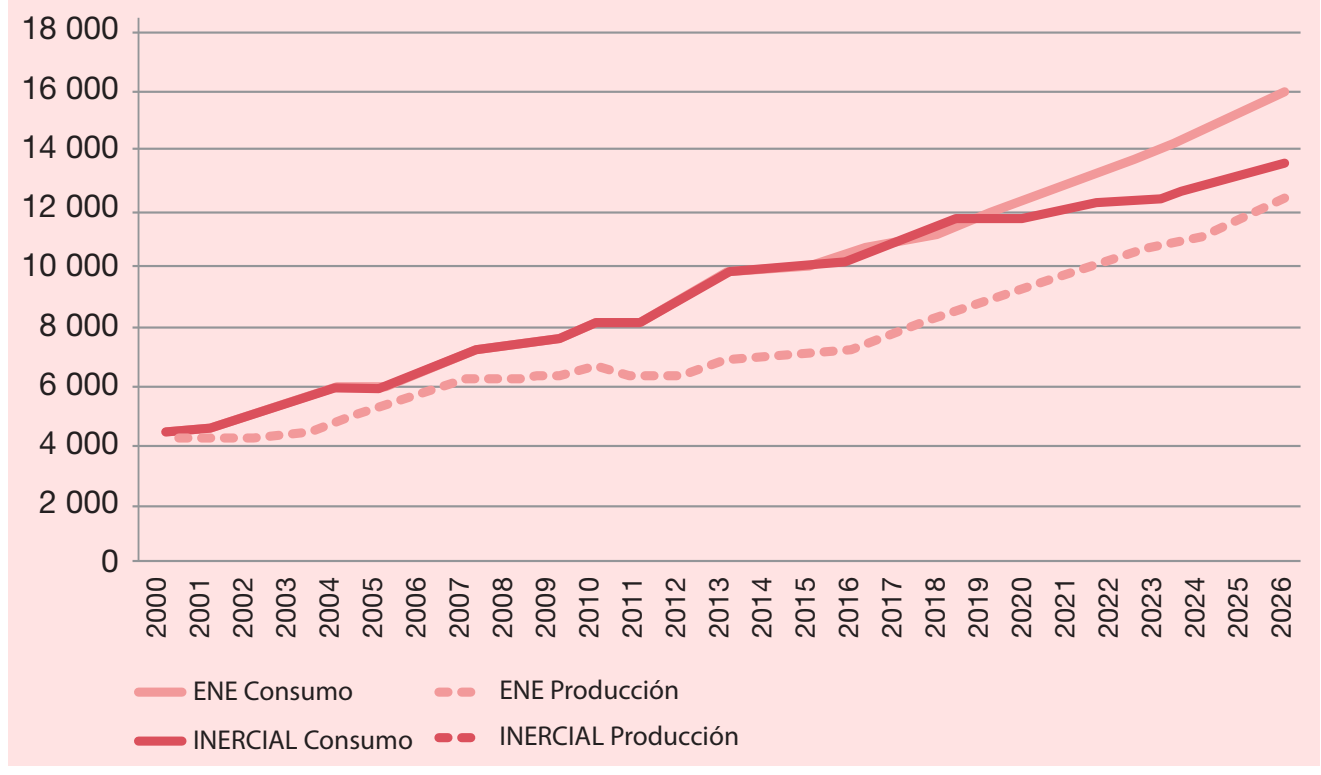

Fuente: Sener, México: Perspectivas para el desarrollo de gas y aceite de lutitas (Shale gas/Oil). Presentación, octubre 2012.

Por otro lado, Estados Unidos no es el único país con interés de producir, y exportar eventualmente, gas natural. Según estudios de la EIA, países como Rusia, China, Argentina y Libia tienen grandes recursos de gas de lutitas. Si bien no todos los países cuentan con los elementos necesarios para desarrollar tal industria en el corto y mediano plazo, es posible que en el largo plazo se desarrollen mercados de gas más integrados. Una empresa productora de gas en Estados Unidos tendrá mayores incentivos para tratar de vender dicho hidrocarburo en Europa a un precio de 11.03 uSD/MmBtu, y no en América del Norte a un precio de 3.6 uSD/ MMBtu.

Con el posible éxito de la extracción de gas en otros sitios además de Estados Unidos, este energético accederá a mercados más diversos y crecientes con la participación de más actores y tomadores de decisión. Esto demandará marcos e instituciones reguladoras, al presentarse una mayor competencia en las diferentes etapas de la cadena delgas natural.

\section{El potencial de shale gas y su significado económico para México}

La dinámica de la industria del gas natural en México se explica en gran medida, por la fuerte relación de dependencia en materia de abasto y de precios, que existe con el mercado de Estados Unidos.

\footnotetext{
9 Promedio del Henry Hub en 2013 con base en datos de la EIA.
} 


\subsection{Abasto de gas natural}

Desde principios del año 2000 ha sido constante la necesidad de importar mayores volúmenes de gas para satisfacer la demanda interna. Tan solo de 2000 a 2013 el consumo ha crecido en promedio 6.2\% cada año, mientras que la producción únicamente lo ha hecho en $3.6 \%$, lo que se ha reflejado en una tendencia creciente a aumentar las importaciones. Éstas, en el periodo señalado, han crecido 19\% anualmente y el año pasado 30\% de la demanda nacional fue cubierto con importaciones, fundamentalmente de Estados Unidos a través de gasoductos.

En el escenario descrito más arriba,en el cual la caída de la producción y el aumento de las importaciones eran las constantes, un estudio publicado por la EIA en $2011^{10}$ situó a México en el cuarto lugar a nivel mundial con los mayores recursos de shale gas. ${ }^{11}$ El dato proporcionado, $681 \mathrm{Bpc}$, significaba una cifra 11 veces superior a las reservas 3P de las que disponía el país en 2011 y vino a replantear las expectativas gubernamentales (Sener 2011). Se sostuvo entonces que el incremento en la oferta de gas natural favorecería el desarrollo productivo sosteniendo que: 1) promovería la inversión, ya que la explotación de shale gas podría atraer entre 7 y 10 mil millones de dólares anualmente; 2) se generarían empleos, puesto que durante los siguientes 15 años podrían generarse hasta 1.5 millones de empleos directos e indirectos; 3 ) se fortaleceria la industria energética nacional al desarrollarse cadenas de valor, hacia la petroquímica, por ejemplo y 4) se reducirian las importaciones de gas natural, fortaleciendo la seguridad energética y reduciendo la dependencia energética del exterior. Es necesario revisar seriamente esas evaluaciones y considerar sus hipótesis y bases factuales. ${ }^{1}$

El optimismo de aquel momento fue plasmado en diversos documentos de la Secretaría de Energía. En la Prospectiva del mercado de gas natural 2012, por ejemplo, se proyectaron dos escenarios: el Inercial y el Estrategia Nacional de Energía ("Escenario ENE"), con una diferencia entre ambos: el segundo incorpora una mayor producción de shale gas.

La gráfica 4 ilustra los escenarios planteados por la Secretaría de Energía, en ellos se puede observar que la producción y el consumo son similares hasta el año 2018, a partir de este año y hasta 2026 las cosas cambian: en el "escenario ENE" el consumo crecerá $4.2 \%$ y la producción $5.2 \%$ cada año, mientras que el

10 EIA,Word Shale Gas Resources: An Initial Assessment of 14 Regions Outside the United States. April 2011. Dicho estudio fue actualizado en Junio de 2013 y apunta que México ocupa ahora el sexto lugar a nivel mundial con $545 \mathrm{Bpc}$ de shale gas técnicamente recuperables.

11 Es importante señalar que la EIA usa el término: "Technically Recoverable Shale Gas Resources", el cual de ninguna manera corresponde a reservas, mucho menos probadas.

12 Las evaluaciones gubernamentales se basan muchas veces en informes de las empresas. En Estados Unidos se han estudiado los informes provenientes de la industria acerca de los impactos económicos del shale gas: ingresos, empleos, impuestos. En un artículo en el cual se hace una revisión de esos informes, el autor (Kinnaman Thomas C., 2011) afirma: "Due to questionable assumptions, the economic impacts estimated in these reports are very likely overstated". 
"escenario inercial" es más reservado, ya que el consumo crecerá $2.3 \%$ y la producción sólo $1.2 \%$ cada año. En ambos escenarios el país seguirá dependiendo del exterior para satisfacer el consumo, pero destaca el hecho de que en el escenario ENE la producción crecerá más que el consumo, contrario a lo que se ha observado en los últimos años.

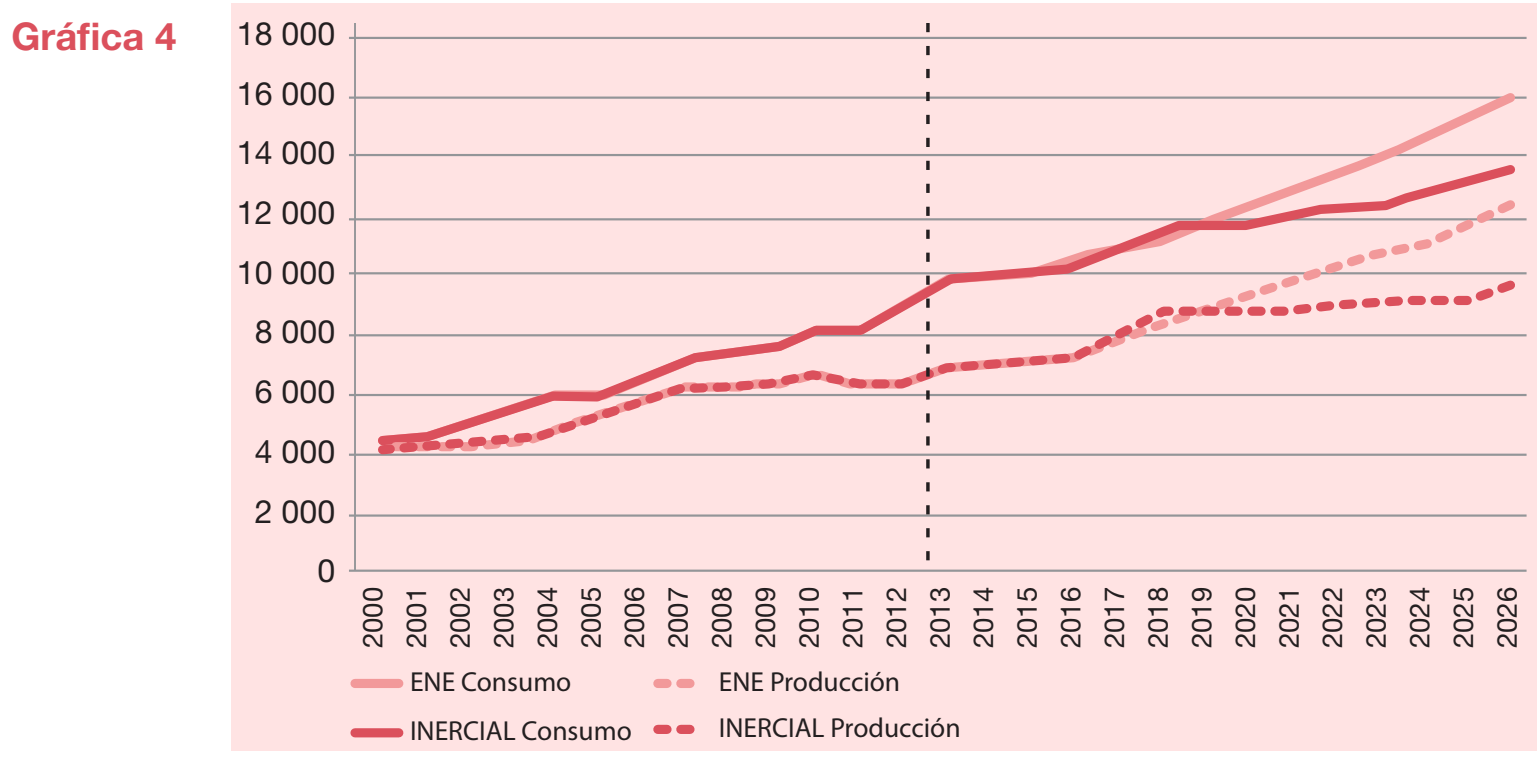

Fuente: Prospectiva del mercado de gas natural 2012.

Otro estudio de la Sener que refleja el optimismo que se tenía ante el papel del shale gas, fue el publicado por tal dependencia en octubre de 2012, titulado "México perspectivas para el desarrollo del gas y aceite de lutitas". En este estudio se llegó a estimar, contrariamente a lo que había reconocido en la Prospectiva del mercado de gas natural 2012, que México se volvería tarde o temprano exportador de gas natural. La justificación era el planteamiento de dos escenarios: el primero, "shale gas marco legal actual" supone que de no haber cambios a la legislación, México importará gas hasta el año 2022; el segundo, "shale gas con esfuerzo adicional" señala que de haber cambios a la legislación se dejaría de importar gas en 2019. Sin embargo en éste último escenario planea supuestos poco probables: como un incremento de más de 300\% del presupuesto que destina Pemex a los proyectos que se desarrollan en la actualidad.

La situación deficitaria en el abasto de gas natural no siempre ha sido así, ya que en 1993 únicamente 3.4\% del consumo era cubierto con importaciones, dato que contrasta con $31 \%$ de 2012. Estaba latente, sin embargo, un problema estructural: la demanda crecía más de lo que se estimaba (alentada por las centrales de ciclo combinado) y las reservas probadas (relación reservas/producción) estaban a la baja. En ese contexto, se señaló desde los primeros años de la pasada década (Adrián Lajous, 2003), que la caída en las reservas probadas no podría sostener la producción necesaria y que era indispensable asignar más 
recursos a la exploración. Sin embargo, poco se hizo para revertir esta situación y las reservas probadas que en 1991 eran de 71 años, en 2003 cayeron a 10 años y en 2012 llegaron a un mínimo de 6.2.

En este contexto, suponer que la producción aumentará en niveles que permitan al país ser autosuficiente en materia de gas natural, y convertir al país en exportador en el corto plazo resulta aventurado. Sobre todo porque implica el romper con la tendencia decreciente del nivel de reservas probadas, originada por la falta de inversión en la exploración y la falta de visión sobre el crecimiento de la industria.

De concretarse el potencial del país con el gas de lutitassería posible revertir la caída en las reservas probadas. Pero es importante tener presente que el problema del gas natural no es únicamente la caída de producción y reservas sino que es de carácter estructural. Se necesita una mayor infraestructura en el transporte, mayores inversiones en la exploración, mejores estimaciones en la demanda para un uso más eficiente de los ductos, más competidores en la cadena de valor de la industria etc. Pero también es necesario replantearse, si el esquema actual de precios contribuye a detonar el crecimiento de la industria.

\subsection{El papel de los precios}

A principios de la década de los noventa, se decidió que los precios del gas natural en México, se fijarían en adelante considerando los costos alternativos de suministro en una economía abierta (costo de oportunidad) en el mercado relevante y más cercano, es decir el de Estados Unidos. Para fijar el precio del gas al interior del país, se toma como referencia el precio del gas en Henry Hub, Lousiana, de tal suerte que Pemex no influye en su fijación y únicamente es tomador de precios.

El "boom" del shale gas en Estados Unidos a partir de 2008, ha impactado el nivel de reservas y producción en dicho paísprovocando una disminución del precio. La gráfica 5 muestra el comportamiento de los precios del gas en Estados Unidos y en México de 2008 a 2014; en ella destaca la caída en los precios a mediados de 2008 y su tendencia a mantenerse bajos, promediando 3.82 usD/ MMBtude 2009 a la fecha.

Cuando el país decide fijar el precio del gas natural bajo el principio del costo de oportunidad, logra trasparentar el mecanismo mediante el cual fija los precios, y al mismo tiempo replica las condiciones de un mercado como el de Estados Unidos (sur de Texas). Sin embargo renuncia a otros factores, por ejemplo, la variación en los precios refleja la escasez o abundancia del recurso en aquel país y no en México, de tal suerte que en nuestro país, a pesar de que las reservas están en una clara tendencia a la baja, los precios también lo están. En este contexto Pemex puede no tener incentivos para explorar nuevos yacimientos; estamos así ante un escenario en el que los precios bajos actuales pueden inhibir la inversión. Al respecto la Secretaria de Energía, ${ }^{13}$ estima que un precio de equilibrio que haría

13 Prospectiva de Gas natural y Gas L.P 2013-2027. 
rentables los proyectos de shale gas oscila alrededor de los 4.0 usD/MmBtu. Por su parte, un estudio del $\mathrm{MIT}^{14}$ apunta que tal precio tendría llegar hasta los 6.0 usD/ MMBtu.

Gráfica 5

Precios del Gas Natural 2008- julio 2014

(Henry Hub)

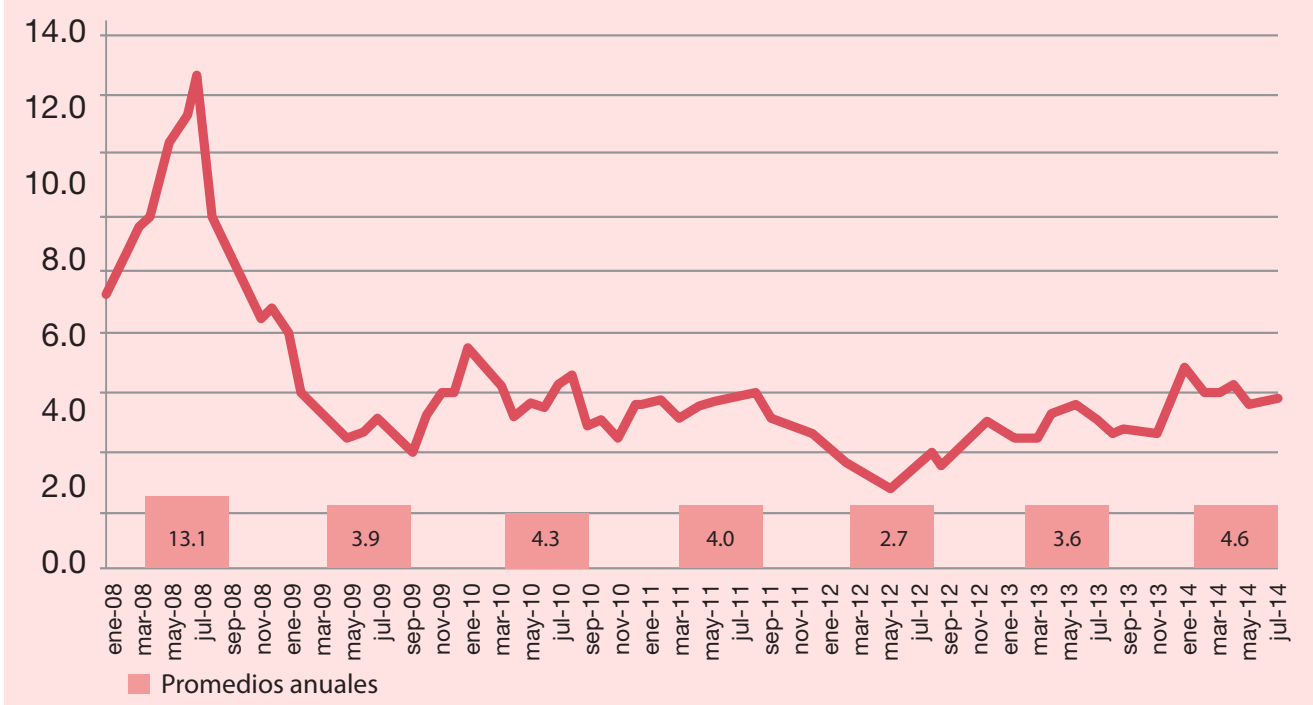

Fuente: elaboración propia con base en datos de la Energy Information Administration (EIA). Gráfica actualizada a fines de julio de 2014.

Por lo señalado hasta aquí surge la necesidad de replantearse el esquema actual de precios y su importancia para detonar el desarrollo de la industria, en especial para el impulso del gas de lutitas.

\subsection{Posibilidades reales para su extracción}

El papel protagónico que se ha dado al gas de lutitas, obedece al gran nivel de recursos que se ha dicho dispone el país, a pesar de que aún no se conoce con certeza el nivel de reservas. Basta mencionar que Pemex inició la evaluación del potencial de shale gas en 2010 identificando cinco provincias geológicas: Chihuahua, Sabinas-Burro-Picachos, Burgos, Tampico-Misantla y Veracruz, detectando un potencial entre 150 y $459 \mathrm{Bpc}$, un dato evidentemente poco preciso. La Secretaría de Energía (ENE-2013) por su parte apunta que los recursos ascienden a 300 Bcf, siendo Sabinas, Burro-Picachos, Burgos, Tampico-Misantla y Veracruz las principales provincias geológicas. Los datos de estas dependencias contrastan con los 545 Bpc que el último informe de la EIA (2013) otorga al país. Para solucionar éste problema, el Instituto Mexicano del Petróleo (IMP) desde marzo de 2013 está a cargo del estudio "Asimilación y desarrollo de tecnología en diseño, adquisición, procesado e interpretación de datos sísmicos 3D-3C con enfoque

\footnotetext{
14 MIT Study on the Future of Natural Gas, 2011.
} 
a plays de shale gas/oil en México". Este estudio busca dar certidumbre al nivel de reservas del país, así como ubicar los mejores sitios para perforar y con ello maximizar el flujo de hidrocarburos.

Pemex se ha dado a la tarea de realizar inversiones para explotar el gas de lutitas; de 6 pozos de exploración perforados entre 2011 y 2012, en 4 se encontró el gas en cuestión y únicamente de 2 de ellos se obtuvo alguna producción. El primero, Emergente 1, en Hidalgo, Coahuila, se sitúa en la continuidad del play Eagle Ford; el segundo, Percutor 1, está ubicado a 150 kilómetros de Emergente 1.

Dada la naturaleza de esos yacimientos, la declinación de los mismos ha sido una constante: en febrero de 2011 Emergente 1 producía 3 mmpcd, para diciembre de ese año 1.5 mmpcd y para septiembre de 2012 apenas rebasó el millón de pies cúbicos diarios. Respecto a Percutor 1, en octubre de 2011 producía 2.2 мmpcd y en marzo de 2012 bajó a 1.7 mmpcd.

El número de pozos de exploración perforados es insuficiente para proporcionar certidumbre respecto a las reservas de gas de lutitas, así como sobre la capacidad financiera, técnica y de gestión de Pemex para extraer tal hidrocarburo. La complejidad del shale gas, en particular, requiere de mucho tiempo e importantes inversiones, tanto en exploración como en producción. En el marco vigente hasta las reformas recientes, solamente Pemex podía hacerse cargo de esas actividades y de buscar los correspondientes financiamientos.

En el contexto actual se presentan dos alternativas para hacer frente al creciente volumen de importaciones de gas natural:

La primera es continuar con la dependencia del gas de Estados Unidos para cubrir la demanda, impulsando aquella infraestructura que permita importar volúmenes crecientes de gas, tanto por gasoductos como por metaneros (GNL). Sin embargo, tal opción no parece sostenible en el mediano y largo plazos, sobre todo cuando se espera que la oferta de gas de Estados Unidos afecte al mercado de Norteamérica y a otras regiones del mundo. Es importante tener presente que en la medida que disminuyan sus importaciones probablemente empiece a exportar gas a otras regiones que tienen precios más elevados. ${ }^{15}$

La segunda es darse a la tarea de crear las condiciones necesarias para explotar los yacimientos de shale gas y con ello asegurar la autosuficiencia de gas natural. Impulsar la extracción de gas de lutitas y que esto sea un detonador de la industria del gas natural en México es una tarea compleja que se sitúa en adelante en el contexto de las reformas constitucionales de diciembre 2013 y de las leyes secundarias votadas entre julio y agosto de 2014. Esta segunda alternativa exige mayor reflexión y análisis, sobre todo porque involucra una visión de lo que se desea sobre la industria en el largo plazo y lo que se espera de ella.

El gas de lutitas puede desempeñar un papel fundamental para un crecimiento de la industria, que se refleje en mayores beneficios económicos para el país. Pero para que ello sea una realidad, será necesario sentar aquellos elementos que detonen su crecimiento, por ello tiene sentido plantearnos las siguientes preguntas:

15 Los precios Norteamérica son de los más bajos en el mundo: hacia mediados de 2013 en la Unión Europea promedian 10.61 uSD/MMBTU y en el Reino Unido están en 9.02 uSD/MMBTU. 
1. ¿Es posible que se puedan replicar en México, aquellas condiciones que favorecieron el "boom" del shale gas en E.u?

2. ¿Proporcionará la Reforma energética el marco adecuado para el desarrollo del shale gas?

3. Considerando la incertidumbre en materia ambiental que dicha actividad entraña, ¿̇es conveniente aventurarse a explotar dicho recurso, o habrá que esperar a tener mayor certidumbre sobre los impactos sobre el medio ambiente?

Las respuestas a estas preguntas poseen implicaciones políticas, económicas y ambientales que las hacen complejas de resolver, sin embargo en el siguiente apartado intentaremos algunas aproximaciones.

\section{Posibilidades y retos para el desarrollo del shale gas}

Como fue expuesto, la Sener tomó una postura poco conservadora ante el estudio de la EIA (2011), el cual sostenía que el país contaba congrandes volúmenes de recursos de shale gas. En el más alto nivel se expusieron de manera exageradamente optimista los beneficios que traería su explotación, un optimismo que se ha abandonado recientemente en aras de una posición más conservadora.

La Prospectiva del mercado de gas natural 2012-2026 planteaba dos escenarios prospectivos al año 2026, ambos con la participación del gas de lutitas en la oferta de gas. En ese mismo documento, el Secretario de Energía afirmaba que el contexto era idóneo para impulsar el gas de lutitas: "Resulta innegable que debemos aprovechar esta coyuntura excepcional para lograr una explotación responsable y sustentable de este recurso, en beneficio de nuestro país y ya estamos dando pasos definitivos para identificar y estimar, de forma más precisa y detallada, los recursos potenciales de shale gas en nuestro país". ${ }^{16}$ Para la Prospectiva de gas natural 2013 las menciones al gas de lutitas son marginales, sólo se plantea un escenario prospectivo y su aportación de cara a satisfacer la demanda en el horizonte de 2027 es marginal.

El hecho que la presente administración tomara desde el principio de 2013 una visión más conservadora, puede ser explicado por las dificultades que supondría impulsar la explotación de shale gas con base en una única empresa y el convencimiento de que se requería una dinámica distinta a la que podía ofrecer Pemex. Al aprobarse las reformas, sin embargo, parece regresar la euforia que prevaleció al publicarse los informes citados de la EIA y que se expresa no en una voluntad de informar a la sociedad sino de convencerla vía anuncios comerciales en los que parece que todo quedará resuelto: se obtendrá rápidamente el gas que necesita el país, en particular parala generación eléctrica, bajarán los precios, se impulsará el desarrollo regional y la generación de empleos.

16 Prospectiva del mercado de gas natural 2012,p. 15. 


\subsection{Pemex ante el reto del shale gas}

Según la Constitución mexicana, la Nación es propietaria de todos los hidrocarburos depositados en el subsuelo. Además, hasta antes de las reformasPemex contaba con una participación exclusiva en las actividades de E\&P, tanto de petróleo como de gas natural.

En este sentido las operaciones de Pemex resultaban complejas, pues se le exigía maximizar el valor de los hidrocarburos producidos y atender el crecimiento de la demanda de petrolíferos, en un entorno de restricciones tecnológicas y fiscales. Lo anterior, aunado al poder del sindicato de la industria, han dificultado la capacidad operacional y la flexibilidad para cumplir los objetivos fijados de manera eficiente.Con el objetivo de maximizar sus ingresos, Pemex ha favorecido proyectos donde la rentabilidad es mayor, es decir la producción de petróleo crudo.

A diferencia de los Estados Unidos, donde los operadores privados toman las decisiones tomando en cuenta los precios y la dinámica del mercado, hasta ahora los proyectos de gas y petróleo han sido centralizados por el gobierno federal a través de Pemex, para posteriormente ser sometidos a la aprobación de la Secretaria de Hacienda.

Como se ha señalado, el "boom" del gas de lutitas en E.U tuvo como respaldo una industria de los hidrocarburos fuertemente desarrollada, puesta al servicio de los yacimientos de gas no convencionales. En México ha habido un claro interés por desarrollar proyectos de petróleo dado el nivel de ingresos que representan, en detrimento de proyectos de gas natural convencional y no convencional.

\subsection{Problemas estructurales}

El marco regulatorio que regía hasta ahora la industria del gas natural, se fijó con la reforma de 1995, que permite la participación de privados en el transporte, distribución y comercialización de gas natural, actividades antes reservadas a Pemex. A 18 años de esa Reforma las cifras no eran alentadoras: mientras en 1995 la infraestructura de transporte existente perteneciente a Pemex representaba 9 mil km, en 2013 se había incrementado marginalmente por ductos construidos por privados hasta alcanzar $11.1 \mathrm{~km}$, es decir un incremento promedio anual de únicamente $1.2 \%$. Es conveniente señalar que estos ductos de transporte han sido promovidos por la Comisión Federal de Electricidad, la cual ha licitado tal infraestructura con miras a extender su parque de generación, con centrales de ciclo combinado. Si bien la infraestructura de transporte prácticamente no ha crecido, no es el caso de los usuarios de gas natural: en 1995 se contaban 576 mil usuarios y en 2013 con 2.1 millones, es decir un crecimiento de $8 \%$ promedio anual.

El crecimiento en la demanda y una oferta de transporte limitada, han provocado que los gasoductos operen cercanos a su máxima capacidad, dando lugar a 22 alertas críticas $^{17}$ en 2012 . El problema de las alertas críticas fue agravado

17 Una alerta crítica es la declaración que hace el transportista para que los usuarios disminuyan su consumo por un cierto periodo, debido a que las condiciones de operación no son seguras para continuar 
por la caída en la producción nacional, problema que no ha podido ser resulto mediante mayores importaciones de gas de EU, precisamente por la carencia de infraestructura para transportarlo.

La abundancia de gas y los precios bajos en Estados Unidos han fomentado que la política energética de México en materia de gas natural sea la de un país importador, sin muchos incentivos para impulsar la producción interna.Después de todo, se dice, ¿jpor qué habría Pemex de aventurarse a una actividad altamente riesgosa, cuando puede importar el gas a uno de los precios más bajos del mundo?

A la luz de los resultados obtenidos por tal política, vale la pena preguntarse si se ha seguido el camino correcto, dados los problemas que persisten en la industria. Pemex no ha tenido gran interés por la extracción de gas y los privadossólo han estado dispuestos a invertiren el transporte, cuando el proyecto esté apalancado por la CFE.

\subsection{Posibilidades después de la Reforma Energética}

La Reforma constitucional aprobada en diciembre de 2013 abre las industrias energéticas a la iniciativa privada nacional y extranjera. En el caso de los hidrocarburos habrá cuatro modelos de contratos que Pemex podrá llevar a cabo con privados: contratos de servicios (que anteriormente ya se podían llevar a cabo), de licencia, de producción compartida y de utilidad compartida. Se abre así un abanico para la participación de privados con reglas que han concretado las leyes secundarias. Con ello se inicia un largo proceso de implementación de las reformas, no exento de riesgos en parte por carencias y deficiencias del nuevo marco legal y del diseño regulatorio.

El Gobierno Federal, sostiene que esta apertura a la iniciativa privada producto de la Reforma, tendrá como consecuencia: 1) Aumentar la producción de gas natural de los 5 mil 700 millones de pies cúbicos diarios que se generan actualmente a 8 mil millones en 2018 y a 10 mil 400 millones en 2025; 2) Que baje el precio del gas natural gracias a que múltiples empresas podrán invertir y participar en la exploración y extracción de gas natural. Se ha afirmado que el gas natural se ha llegado a importar a un precio de hasta 19 dólares, cuando en México se produciría a tan sólo 3 dólares. ${ }^{18}$

La lógica que sostiene que una mayor oferta alentada por participación de privados entraña una caída en el precio, no es tan sencilla como parece, al menos no para la industria del gas natural en México, ya que el Gobierno plantea supuestos que no recogen las características de la industria.Un ejemplo: el precio del gas natural se fija mediante la "Directiva de precios" la falta de competencia efectiva los precios se fijan bajo el principio del costo de operando el gasoducto. Se trata básicamente de un desbalance entre una demanda más grande y la capacidad de transporte para satisfacerla.

18 Presidencia de la República, 21 de diciembre de 2013.

19 CRE, Directiva sobre la determinación de tarifas. 
oportunidad. De esta manera,mientras no exista una competencia efectiva o sea derogada tal Directiva, las condiciones de escasez o abundancia del recurso en territorio nacional no afectarán el precio del gas.

Es importante aclarar que el planteamiento del gobierno de que el gas que se importa está a 19 uSD/Mm/Btu es engañoso, pues ese precio corresponde a las importaciones de GNL,las cuales representan únicamente $6.7 \%$ del consumo nacional, siendo su destino principal las centrales de ciclo combinado de CFE. Las importaciones de GNL se han dado recientemente para balancear el sistema, ante la falta de ductos de transporte para importarlo de Estados Unidos, a pesar de que esto último es más económico (siempre y cuando la red de gasoductos fuera más robusta).

La Reforma plantea una mayor competencia en la cadena de valor del gas natural, pero en ese nuevo marco las señales que envíen los precios que reciban los productores y transportistas no deben inhibir las inversiones, como sucede en la actualidad.

\subsection{Perspectivas futuras}

El optimismo del Gobierno en materia de gas natural, se manifiesta en posturas con poco sustento: se dice la meta pero no el camino para llegar a ella. La publicidad en torno a la Reforma Energética asegura una caída en los precios del gas, alentada por mayores inversiones y un mayor nivel de producción, pero se desconocen las políticas concretas que serán implementadas para alcanzar tales objetivos.

Si bien el camino que sentó las bases para el boom de gas de lutitas en Estados Unidos tuvo su origen en una combinación de factores técnicos, económicos e instituciones, no quiere decir que ese camino sea el único posible. Oficialmente se sostiene, sin embargo, que en la economía mexicana se pueden adecuar algunos elementos de esa combinación con el fin de detonarla explotación del shale gas. De hecho éste es el sentido de la reforma energética de finales de 2013 al buscar la participación de un mayor número de agentes en exploración y explotación de hidrocarburos.

Con la reforma energética Pemex, con la salvedad de la "Ronda cero"20 (a través de la cual la Sener le adjudicará yacimientos sin que tenga que competir en licitaciones), tendrá que competir con los diversos participantes o aliarse con ellos para la adjudicación mediante licitación de contratos de exploración y extraccióna cargo de la Comisión Nacional de Hidrocarburos. También se considera la participación de Pemex en toda la cadena de valor incitándolo a pasar de su

20 La "Ronda Cero" es el proceso mediante el cual Pemexsolicita asignaciones de extracción, en los yacimientos donde desea continuar los trabajos de producción y proporciona un plan de desarrollo que justifica su capacidad para hacerlo (capacidad técnica, financiera y de ejecución). La Sener y la Comisión Nacional de Hidrocarburos verifican que la solicitud sea consistente con los requerimientos de inversión y el proyecto de desarrollo. La Sener podrá otorgar la totalidad o parte de lo solicitado por Pemex a más tardar el 17 de septiembre de 2014. 
estatuto actual a una "Empresa productiva del Estado" con personalidad jurídica, patrimonio propio, autonomía técnica, operativa y de gestión.

Con estos cambios se Busca que Pemex compita en igualdad de circunstancias en la explotación y valorización de hidrocarburos. En el momento de escribir estas líneas se desconocen los resultados de la solicitud presentada por Pemex el pasado 21 de marzo de 2014 como parte de la Ronda Cero. Sólo se puede leer en el portal de la Sener: "En áreas de lutitas, Pemex solicita una fracción de los recursos prospectivos del país con el fin de desarrollar capacidades tecnológicas para su futuro desarrollo". ${ }^{21}$

Será hasta después de la Ronda Cero y con las primeras áreas de licitación cuando se pueda medir el interés del sector privado de participar en esta actividad en la cual tendrá sin duda espacios para participar. Pero el desarrollo de la industria de lutitas no demanda solamente un mayor número de agentes interesados en su extracción; quedan además varios pendientes por definir: ¿Cómo se fomentarán las inversiones cuando el precio de las ventas de primera mano pueden inhibirlas? ¿Cómo se piensa desarrollar una red de infraestructura de transporte de gas, alrededor de los yacimientos de lutitas, cuando prácticamente toda la infraestructura está alrededor de la generación eléctrica? ¿Cómo se resolverán los problemas de los derechos de propiedad donde se alojen los yacimientos? ${ }^{22}$ ¿Cómo se resolverá el problema del agua que requiere el proceso de extracción, cuando dicho recurso es escaso en el norte del país y en otras zonas? ¿Cuál será la normativa en materia ambiental exigida para el gas de lutitas, tomando en cuenta experiencias internacionales y la incertidumbre que existea nivel mundial acerca de sus impactos al medio ambiente? ¿Se impulsará el desarrollo científico tecnológico para no depender únicamente de la transferencia de tecnología? Además de esas preguntas específicas queda una más general ¿tendrá la Empresa Productiva del Estado un lugar preeminente en la industria de los hidrocarburos o será un operador más?

\section{Consideraciones Finales}

Los temas y problemáticas del shale gas no se relacionan solamente con componentes de la cadena de valor, como las actividades de exploración y producción, aunque esas actividades son cruciales cuando un país necesita ese energético y dispone de informaciones acerca de la existencia de recursos en su territorio. Requieren, sobre todo, una visión amplia que considere de manera central la protección al ambiente y las conexiones con la industria eléctrica y con otras que pueden verse favorecidas por diversos impactos industriales y tecnológicos.

Políticas energéticas y ambientales coherentes proporcionan un marco necesario para inversiones de largo plazo, como las que caracterizan al sector energético, así como para el desarrollo de una infraestructura adecuada. Concretamente,

21 http://www.energia.gob.mx/webSener/rondacero/9214.html

22 En este punto debe profundizarse el tema de la expropiación de tierras el cual quedó finalmente en la legislación como "ocupación temporal". 
en el caso del shale gas, es en un marco integral de políticas energéticas, ambientales y tecnológicas donde debe situarse su posible explotación por entidades públicas o privadas. En ese marco toman particular relevancia temas que muchas veces se abordan de manera aislada, como las fugas de metano y todo lo relacionado con la fracturación hidráulica (fracking), las ingentes necesidades de agua y la utilización de químicos tóxicos.

Estados Unidos ha tenido éxitos significativos en la producción del shale gas, a partir de una combinación de factores específicos que hemos analizado y que no se encuuenträn nècesariamente reunidos en otros países. En este sentido la idea de que es posible replicar en otras latitudes los logros de aquel país no tiene bases sólidas, incluso cuando agencias como la EIA informan de la existencia de importantes recursos en diversos países, incluido México.

Asimismo, de confirmarse la existencia de recursos técnica y económicamente recuperables, es necesario aún construir o reforzar un marco regulatorio específico y las instituciones correspondientes que aseguren un adecuado desarrollo. Por ello llama la atención que sólo una vez y de manera incidental se haya mencionado al shale gas o gas de lutitas en la iniciativa de la Ley de Hidrocarburos de la Presidencia de la República. ${ }^{23}$ Considerar que los gases no convencionales pueden impulsarse con el mismo marco regulatorio que los convencionales puede tener importantes consecuencias, sobre todo si se pretende atraer inversiones específicamente para ese campo. El shale gas requiere trato especial: como se ha visto en este trabajo es una industria distinta que requiere un marco regulatorio distinto.

Los precios al alza del gas natural incentivaron en un determinado momento las inversiones necesarias para la expansión del shale gas en Estados Unidos. La decisión del gobierno de México de referenciar el precio del gas natural a los prevalecientes en el sur de Texas, ha tenido consecuencias sobre las inversiones de la industria. Esta situación se ha traducido en caída en las reservas probadas, carencias en la infraestructura de transporte, aumento de las importaciones y una demanda en creciente aumento por los bajos precios. Ese esquema de precios, en consecuencia, debe ser replanteado, buscando incentivar las inversiones y actuar sobre el consumo tomando en cuenta los costos de producción. Un argumento a favor del actual mecanismo de precios fue que limitaría la discrecionalidad de Pemex en la fijación de los precios, al ser el único productor. Sin embargo, con la Reforma Energética y la apertura al sector privado en materia de extracción y exploración, el argumento no se sostiene: la apertura se reflejará en los precios. De lo contrario difícilmente la reforma atraerá inversiones en materia de shale gas y se mantendrá la tendencia a ser un importador neto con las problemáticas que ello entrañe.

La aprobación de las leyes secundarias, que proporcionarán el marco para el desarrollo de las industrias energéticas, debe dar lugar a trabajos especializados, intensa información y formación de recursos humanos en distintos niveles, disciplinas y especialidades. El país se está abriendo a prácticas usuales en el plano

23 “...¿̇en atención a las características de alto riesgo existentes en algunas actividades de la industria petrolera (extracción en aguas profundas y ultra profundas, o producción de aceite y gas de lutitas, por ejemplo) en la mayoría de los países, éstas se llevan a cabo de manera conjunta por diversos actores". 
internacional, pero desconocidas hasta ahora en México por la persistencia de la forma de organización de la industria de los hidrocarburos. Serán muy costosos los descuidos al concretar temas como los términos de los contratos, el papel y funciones de las agencias de regulación, el tipo y grado de involucramiento de Pemex olas regulaciones ambientales.Aún si se hace todo con el máximo de corrección posible, en los tiempos establecidos, los resultados no se verán inmediatamente. Es necesario teneresto presente, en particular para el caso del shale gas sobre el cual, como se ha visto en este trabajo, se fincaron en años pasados expectativas sin fundamento.

\section{Bibliografía}

Arora Vipin, Lieskovsky Jozef [2014], "Natural Gas and U.S. Economic Activity", The Energy Journal, Vol. 35, núm. 3.

Blackwill Robert D., O'Sullivan M.L., [2014], "The Geopolitical Consequences of the Shale Revolution", Foreign Affairs, March/April.

Bravo Víctor [2013], "Una opinión sobre el fracking", Fundación Bariloche, Departamento de Economía Energética, Documento de Trabajo, septiembre, 25 p.

Cornot-Gandolphe Sylvie [2014], "Gaz de schiste en Pologne, au Royaume-Uni, et au Danemark: vers un modèle européen?", Note de L'IFRI, $41 \mathrm{p}$.

CRE [2007], Directiva sobre la determinación de tarifas y el traslado de precios para las actividades reguladas en materia de gas natural, DIR-GAS-001-2007, 28 de diciembre.

Di Sbroiavacca Nicolás [2013], "Shale oil y shale gas en Argentina. Estado de situación y prospectiva", Fundación Bariloche, Departamento de Economía Energética, Documento de Trabajo, agosto, $20 \mathrm{p}$.

Energy Information Agency (EIA), Annual Energy Outlook 2012.

Estrada Estrada Javier [2011], El papel del gas shale en México: consideraciones económicas y regulatorias, Energía a Debate, Noviembre 1, http://energiaadebate. com/el-papel-del-shale-gas-en-mexicoconsideraciones-economicas-y-regulatorias/

Estrada Estrada Javier [2013], Desarrollo del gas lutita (shale gas) y su impacto en el mercado energético de México: reflexiones para Centroamérica, CEPAL, Sede Subregional en México, Octubre, $118 \mathrm{p}$.

Freyman Monika [2014], Hydraulic Fracturing \& Water Stress: Water Demand by the Numbers, CERES Report, February, $85 \mathrm{p}$.

Howarth R. W., Santoro R. [2011], Methane and the greenhouse-gas footprint of natural gas from shale formations, School of Civil and Environmental Engineering, Cornell University, Ithaca, USA.

Instituto Mexicano del Petróleo (2012). Informe de rendición de cuentas 2006-2012. Disponible en: http://www.imp.mx/

Kinnnaman Thomas C. [2011], "The economic impact of shale gas extraction: A review of existing studies", Ecological Economics, mayo, pp. 1243-1249.

Jenner Steffen, Lamadrid Alberto J. [2012]. Shale gas vs. coal: Policy implications from 
environmental impact comparisons of shale gas, conventional gas, and coal on air, water, and land in the United States, Energy Policy, no. 53, Elsevier, 442-453.

Lajous Adrián [2003], Seguridad de suministro de gas natural en México. Intervención en el Congreso anual de la Asociación Mexicana para la Economía Energética, México 20 de octubre.

Lajous Adrián [2013], Dilema del suministro de gas natural en México, Publicación de las Naciones Unidas, Sede Subregional de la CEPAL en México, México, D. F., marzo, 50 p.

Lozano Maya J. Roberto [2013], La producción global del gas de lutita, ¿revolución para todos? Energía a debate, febrero.

Lozano Maya J. Roberto "The United States experience as a reference of success for shale gas development: The case of México", Energy Policy, No. 62, pp. 70-78.

Martínez de Hoz, Lanardonne, Maculus [2013], Shale we dance an unconventional tango?", The Journal of World Energy Law \& Business, Advance Access, July 12, Oxford University Press.

Medlock III Kenneth Barry (2012). "Modeling the implications of expanded us shale gasproduction", Energy Strategy Reviews, Energy Forum, James A Baker III Institute for Public Policy, Rice University.

MIT [2011], "The Future of Natural Gas, An Interdisciplinary Study", Capítulo 2 Apéndice 2D on the Future of Natural Gas, Junio. http://mitei.mit.edu/system/files/NaturalGas_ Appendix2D.pdf

Olmstead Sheila, Richardson Nathan [2014], "Managing the Risks of Shale Gas Development Using Innovative Legal and Regulatory Approaches", Resources for the Future, Discussion Paper, June, $24 \mathrm{p}$.

Peltier Robert (2013), "Should the U.S. Export Natural Gas?",Power bussiness and technology for the global generation industry. Obtenido el 1 marzo de 2014 de: http://www.powermag.com/gas/5387.html.

Rinkenbach Lizárraga José Pablo [2013],"Viabilidad económica de la explotación del shale", Energia a Debate, Noviembre / Diciembre.

Rodgers Deborah [2013], "Shale and Wall Street: Was the decline in natural gas process orchestrated, Deborah Rodgers", Energy Policy. Forum, Febrero.

Sandrea Rafael [2012] "Evaluating production potential of mature us oil, gas shale plays", IPC Petroleum Consultants, 12 deMarzo, www.ogj.com

Sener [2012 y 2013], Estrategia Nacional de Energía.

Sener [2012]. Prospectiva del mercado de gas natural 2012-2026.

Sener [2013]. Prospectiva de Gas natural y Gas L.P 2013-2027.

Sener (2012). Sexto Informe de Labores. Disponible en: http://www.sener.gob.mx/

Sener [2011]. Discurso del Secretario de Energía el 17 de noviembre de 2011. Disponible en http://www.energia.gob.mx/portal/Default.aspx?id=2074

Sovacool Benjamin (2011),"National energy governance in the United States", Journal of World Energy Law and Business, Vol. 4, núm. 2, Oxford University Press, pp. 97-123.

Taha Murtuza Husain Et. Al. [2011], "Economic Comparison of ulti-Lateral Drilling over Horizontal Drilling for Marcellus Shale Field Development". Final Project Report, EME 580: Integrative Design of Energy \& Mineral Engineering Systems, 1 de mayo. 
Trembath Alex, Jenkins Jesse, Nordhaus Ted, and Shellenberger M. [2012], Where the Shale Gas Revolution Came From. Government's Role in the Development of Hydraulic Fracturing in Shale, Breakthrough Institute Energy \& Climate Program. Obtenido el 31/03/ 2013: http://thebreakthrough.org/blog/Where_the_Shale_Gas_ Revolution_Came_From.pdf

U.S. Energy Information Administration (EIA) [2010], World Shale Gas Resources: An InitialAssessment of 14 Regions Outside the United States, Abril.

U.S. Energy Information Administration (EIA) [2013], Technically Recoverable Shale Oil and Shale Gas Resources: an assessment of 137 shale formations in 41 countries outside the United States, junio.

U.S. Energy Information Administration (EIA) [2012], Annual Energy Outlook 2012

U.S. Council of Economic Advisers [2014], The all-of-the-above energy strategy as a path to sustainable economic growth, May 2014, 43 p.

Vengosh Avner, Warner N., Jackson R., Darrah T.[2013], "The effects of shale gas exploration and hydraulic fracturing on the quality of water resources in the United States", Procedia Earth and Planetary Science 7, pp. 863-866.

World Energy Council [2010], "Survey of Energy Resources: Focus on Shale Gas", 36 p.

Word Energy Council [2011], "Survey of energy resources: shale gas. What's new", 16 p.

\title{
Siglas y unidades
}

\author{
Bcf/d: Billions of Cubic Feets/daily \\ Btu: British Thermal Unit \\ EIA: Energy Information Administration \\ GNL: Gas Natural Licuado \\ MM: millones \\ USD: dólares de los Estados Unidos
}

